www.jmscr.igmpublication.org

Impact Factor 3.79

Index Copernicus Value: 5.88

ISSN (e)-2347-176x ISSN (p) 2455-0450

crossref DOI: http://dx.doi.org/10.18535/jmscr/v3i12.53

\title{
Occupational Therapists Perspective in Wound Care Management
}

\author{
Author \\ S. Sathish Kumar \\ Sr. Occupational Therapist \& In-charge, Department of Occupational Therapy, \\ JIPMER, Puducherry and Research Scholar, Himalayan University, Arunachal Pradesh \\ Email: sathsee04@yahoo.co.in
}

\section{Introduction}

Occupational Therapists play a major role in prevention and management in skin and wound care. Wounds and injuries can restrict persons participation in day to day activities e.g. Self care. Wounds can be of physical Injuries and mental disabilities like e.g. Depression, decreased social participation. As a part of rehabilitation team Occupational Therapists' role plays in helping the clients return to pre injury physical and emotional function ${ }^{(1)}$.

The strategies followed by Occupational Therapist in wound care:

1. Management of client's health status.

2. Prevention of pressure/friction wounds.

3. Bowel and bladder incontinence maintenance.

4. Mobility status

5. Environmental modification.

6. Mental status evaluations.

7. Activities of daily living.

8. Provide references to other ancillary services.

\section{Health Management}

- Identify the causative factors for injury/infection.

- Client education regarding risk of infection.

- Providing guidance to the patients with regards to avoiding materials which causes pressure to the wounds which leads to delay in healing.

- Patient's cognitive function is improved by providing information regarding management of wound and provision of separate wound care plan to individual clients.

\section{Pressure Management}

This stage comprises of bed mobility, transfers, supportive aids and adaptations, safety and protection, anti deformity positioning.

- Bed mobility: Assessment of patient's functional status and necessary equipment is provided to access patient's mobility in bed.

- Transfers: clients are educated regarding shifting of body weights with and without caregiver's assistance. 
- Supportive aids and adaptations: Clients are educated in handling supportive aids and adaptations to manage with wounds/injury.

- Safety and protections: Adaptations, modifications in dressing to suite patient needs which is of easy wear, good ventilation, dresses with loose fitting to prevent pressure on wounds.

- Antideformity positioning: Clients with decreased cognition, altered sensation and decreased mobility needs periodic intervention. Strategies like time scheduling for position changes splints are suggested to prevent pressure.

\section{Bowel and Bladder in Continence}

Health education regarding effects of poor hygiene (bowel and bladder in continence) which causes deleterious skin which leads to infection.

- Usages of equipment like commode, cushion covers are suggested.

- Education regarding management of toileting with adaptive aids. e.g. Independent management of catheters etc.

\section{Mobility}

- Steps to improve mobility to improve/maintain mobility.

- Aids like wheel chair are assessed and appropriate seating is adapted to maintain skin integrity.

\section{Environment}

Based on clients home and hospital safety assessment the environmental barriers are identified and modified accordingly.

\section{Mental Status}

- Client's perceptual and cognitive function is evaluated.

- Provision of self-care plan to motivate client.
- Assessment o f psychosocial factors e.g. Isolation, motivation etc. and treated accordingly.

\section{Activities of Daily Living}

- Clients activities which leads to skin problems for a day is analyzed and education is given to them regarding safe usage of materials'

- Encourage nutrious meals to promote healing with dietician's advice.

\section{References to Other Ancillary Services \\ - References to Orthotic/Prosthetics department for appropriate foot wear \\ - Refer to special clinics.}

\section{Conclusion}

Wounds and skincare management comprises of different stages like prevention of wound, treatment of wound care, and health education to the person regarding self management of wound. With the above stages when provided leads to occupational therapy as a full fledge treatment with at most care giving psychological support in day to day activities.

\section{Acknowledgement}

I hereby acknowledge

1. Dr. Jagdish Menon

Professor \& Head of Department of Orthopeadics, JIPMER.

2. Dr. Navin Kumar Agarwal

Asst. Professor Physical Medicine Rehabilitations, JIPMER.

\section{Reference}

1. Heidi Mc Heigh Pendilon,Winifred Schultz-Krohn.Pedretti's, Occupational Thearapy - Practice Skills For Dysfunction. $6^{\text {th }}$ ed.USA: Mosby Year Book, Inc, Harcourt Brace \& Company \& Asia Pte Ltd 1998. Chapter39, Hand and Upper Extremity Injuries; p1015 